\title{
Rotatory Condition at Initial Stage of External Spline Rolling
}

\author{
Da-Wei Zhang, ${ }^{1}$ Sheng-Dun Zhao, ${ }^{1}$ and Yong-Tang $\mathrm{Li}^{2}$ \\ ${ }^{1}$ School of Mechanical Engineering, Xian Jiaotong University, Xian 710049, China \\ ${ }^{2}$ School of Materials Science and Engineering, Taiyuan University of Science and Technology, Taiyuan 030024, China \\ Correspondence should be addressed to Da-Wei Zhang; zhangdawei2000@mail.xjtu.edu.cn
}

Received 29 August 2013; Accepted 27 November 2013; Published 12 January 2014

Academic Editor: Bo Yu

Copyright (C) 2014 Da-Wei Zhang et al. This is an open access article distributed under the Creative Commons Attribution License, which permits unrestricted use, distribution, and reproduction in any medium, provided the original work is properly cited.

\begin{abstract}
In spline rolling process, the billet is mainly driven by frictional moment at initial forming stage that from starting rolling to billet/workpiece rotated half circle. If the rotation of billet is not normally driven by rolling die, then the motion between billet and rolling die is not coordinated, and then dividing precision of external spline will be reduced. Thus, the rotatory condition of rolled billet was established in this work. The rotatory condition for the rolling process of spline with even number of teeth is different from that with an odd number of teeth. However, the changing trends for both rotatory conditions are the same. The results indicated that (i) the rotatory condition can be improved when the friction between die and billet increases or the outside diameter of rolling die increases, (ii) the rotatory condition for odd number of teeth is better than that for even number of teeth, and (iii) the outside diameter of rolling die should be five times greater than the diameter of billet before rolling according to the rotatory condition. The reasonable decrement can be selected by comprehensive considering of rotatory condition and geometry of rolling die.
\end{abstract}

\section{Introduction}

The rolling process of external spline is a precision forming technology based on cross rolling. The rolling process has many advantages such as high productivity, efficient material application, high strength, and wear resistance in the flank zone and stable precision of size for rolled parts, especially that it is able to form splined feature but does not affect the integrity of the journal being very close to the spline [15]. Thus, more attention and application are paid to spline cold rolling in the manufacturing of high-strength and highprecision spline shaft.

In consideration of the shape of rolled teeth, the rolling process of external spline can be divided into two stages [6]: (1) dividing-teeth stage, which from starting rolling to billet/workpiece rotated half circle; (2) forming-teeth stage, which from half circle of billet/workpiece rotated to the end of forming process. At the dividing-teeth stage, the flank of workpiece has not been formed, and the rotation of workpiece is mainly driven by frictional moment, that is, driven by rolling die. At the forming-teeth stage, flank of workpiece has been formed, so the motion between workpiece and rolling die can be regarded as generative movement. Then, engagement factor in gear the engagement can be introduced to describe the rotation at forming-teeth stage. However, if billet/workpiece cannot be normally driven by rolling die, then the motion between billet/workpiece and rolling die is not coordinated, and then the dividing precision of spline would be reduced. It is necessary to explore the rotation of billet/workpiece at the initial stage of external spline rolling.

The variables in rotatory condition for simple cross rolling are the ratio of decrement to diameter of billet after rolling and the ratio of diameter of billet after rolling to diameter of rolling die [7], so the rotatory condition is not convenient to determine the decrement. Zhang [8] used the same variables to investigate the rotatory condition for rolling process of spline with even number of teeth, but practical formula has not been developed. Hu et al. [7] established the rotatory condition for cross wedge rolling based on the rotatory condition for simple cross rolling. Celikov determined the range of deformation ratio for cross wedge rolling of hollow parts according to the condition of rolling stable duration [9]. However, the process of spline cold rolling is very different from the process of simple cross rolling or the process of cross wedge rolling due to rolling die with complicated spline features. Thus, we urgently needs to 
study the rotatory condition for spline rolling to understand rotation of billet/workpiece at the initial stage.

Up to now, most scholars focus on process plan, experiment, and numeric simulation [10-15]; the reports in the literature about rotatory condition for external spline rolling are scarce. Thus, it is necessary to establish the rotatory condition at initial stage of external spline rolling and to determine the processing condition of normal rotation and stable forming. In this paper, taking the ratio of outside diameter $\left(d_{a_{d}}\right)$ of rolling die to diameter $\left(d_{Z}\right)$ of billet before rolling, and the ratio of decrement $(\Delta s)$ to $d_{Z}$ as variables, the rotatory conditions for the rolling processes of spline with even and odd numbers of teeth are established, respectively. The differences and similarities between two rotatory conditions are analyzed. The changing laws of the rotatory condition are discussed. The range of decrement is determined according to rotatory condition combined with other parameters.

\section{Descriptions of Forming Process and Force}

The process of spline rolling can be presented as follows $[2,8]$ : two rolling dies with the same spline features are parallelly assembled on two drive shafts, two rolling dies have the angular velocity $\omega_{d}$, and rolling dies with a speed $v$ infeed are synchronized in radial direction. The rolling die provides the frictional moment when it contacts the billet and drives the billet to rotate at an angular velocity $\omega_{w}$. Two rolling dies keep a constant infeeding speed and continual radial-infeed rolling until the corresponding external spline is formed.

In the rolling process of external spline, the displacement and strain in axial direction can be regarded as zero [2]. In practice, the diameter of billet before rolling is also determined according to that the cross-sectional area before rolling is equal to area after rolling. Therefore, the deformation can be regarded as a plane strain deformation.

Two rolling dies have the identical parameters for the spline rolling, but the phase difference between two rolling dies before rolling process of spline with even number of teeth is different from that with odd number of teeth. To form spline with even number of teeth, the phase difference is zero, which means that the tooth space of one die faces the tooth space of the other die, as shown in Figure 1; to form spline with odd number of teeth, the phase difference is $\pi / Z_{d}\left(Z_{d}\right.$ is the number of rolling die teeth), which means that the tooth crest of one die faces the tooth space of the other die, as shown in Figure 2.

Generally, at the initial stage of spline rolling process, the flank of workpiece has not been formed, and the frictional moment drives the billet/workpiece to rotate. On the cross section, the rolling dies apply four external forces, such as the two normal forces $P$ and frictional forces $T$, to billet/workpiece. The force line of $P$ passes the center $\left(O_{d}\right)$ of die and the center $(A)$ of contact area (i.e., line on the cross section). The angle between the force line of $P$ and $\overline{O_{d} O_{w}}$ is $\theta_{d}$, where the $O_{w}$ is the center of billet/workpiece, as shown in Figures 1 and 2.

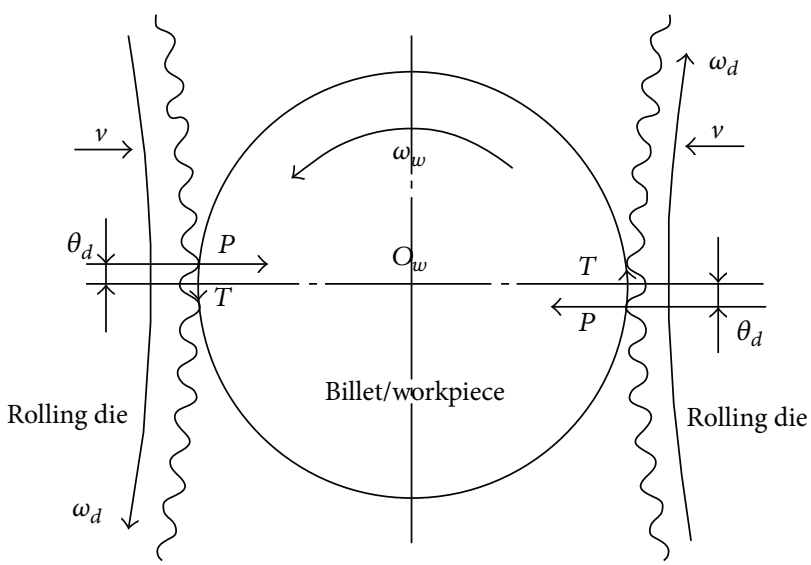

FIGURE 1: Force sketch of spline rolling for even number of teeth.

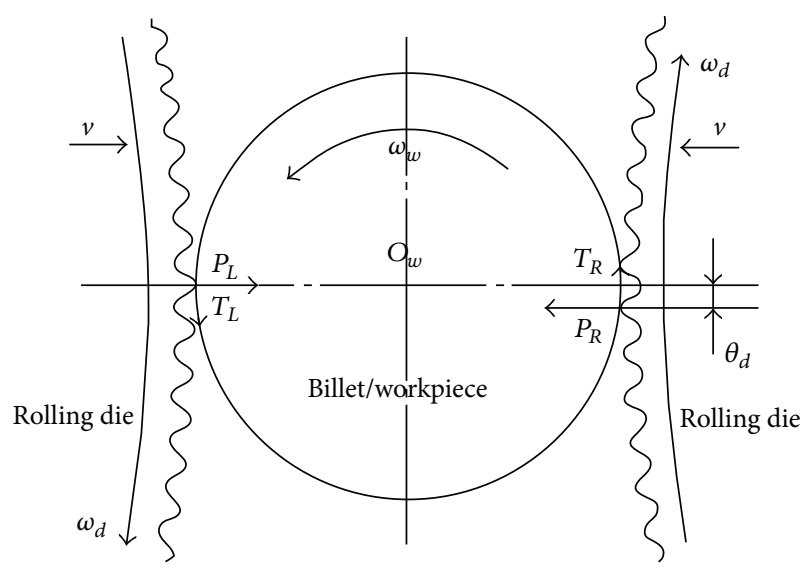

FIGURE 2: Force sketch of spline rolling for odd number of teeth.

Figure 1 illustrates the force in rolling process of even number teeth spline. Two normal forces are exerted on billet/workpiece symmetrically, and two frictional forces are also exerted on billet/workpiece symmetrically.

Figure 2 illustrates the force in rolling process of odd number teeth spline. There also exist four forces which are $P_{L}, P_{R}, T_{L}$, and $T_{R}$, but the forces are not symmetrical.

In the rolling process of even number of teeth spline, the phases of rolling dies are the same, and the contact states between billet/workpiece and dies are symmetrical, and the forces are also symmetrical. However, in the rolling process of odd number of teeth spline, the phases of rolling dies are different, and the forces are not symmetrical. This difference has a notable influence on the rotatory condition of rolled part but a small influence on the deformation, contact area, and rolling force, where the curves of parameters have a little time lag between even and odd numbers of teeth.

\section{Rotatory Condition at Initial Stage of Spline Rolling Process}

The Coulomb friction model was used in derivation of rotatory condition for simple cross rolling [7]. Coulomb friction model was also adopted in this work, so the relation 
between normal force $(P)$ and frictional force $(T)$ can be expressed as follows:

$$
T=\mu P, \quad \mu=\frac{T}{P},
$$

where $\mu$ is friction coefficient.

The condition of billet/workpiece being driven to rotate is that the moment $\left(M_{T}\right)$ of frictional forces must be greater than or equal to the moment $\left(M_{P}\right)$ of normal forces, which can be expressed by

$$
M_{T} \geq M_{P}
$$

Figures 1 and 2 illustrate the force in rolling process for even number of teeth spline and odd number of teeth spline respectively; and the $M_{T}$ and $M_{P}$ are different according to the force sketches, and thus the rotatory condition for even number of teeth spline is also different from the rotatory condition for odd number of teeth spline.

The ratio of decrement to diameter of billet after rolling and the ratio of diameter of billet after rolling to diameter of rolling die are the important parameters in the rotatory condition for simple cross rolling. Is this work, there exist the similar parameters in the expression of rotatory condition at initial stage of spline rolling process, which are the relative decrement and the outside diameter ratio between die and billet. The ratio of decrement $(\Delta s)$ to diameter $\left(d_{Z}\right)$ of billet before rolling is named relative decrement. The ratio of outside diameter $\left(d_{a_{d}}\right)$ of rolling die to diameter $\left(d_{Z}\right)$ of billet is named outside diameter ratio between die and billet. In order to derive rotatory condition conveniently, the outside diameter ratio and relative decrement are expressed as $x$ and $y$, respectively, such as

$$
\begin{gathered}
x=\frac{d_{a_{d}}}{d_{Z}}>0, \\
y=\frac{\Delta s}{d_{Z}}>0 .
\end{gathered}
$$

In the spline rolling process, the contact situation between die and billet/workpiece is "contact-separate-contact." The process from one tooth of die contacting to separating is named one rolling process. In one rolling process, the difference between root radius $\left(r_{f 0}\right)$ of billet/workpiece before die contacting and the root radius $\left(r_{f 1}\right)$ after die separating is defined as decrement, that is, $\Delta s$ used in (3), as shown in Figure 3. The decrement is equal to the feed of one die in half circle of workpiece that rotates at forming-teeth stage.

\subsection{Rotatory Condition in Rolling Process of Spline with Even} Number of Teeth. Figure 4 illustrates the force and moment arm in rolling process for spline with even number of teeth. Moments $M_{T}$ and $M_{P}$ can be expressed as follows:

$$
\begin{aligned}
& M_{P}=P \cdot a, \\
& M_{T}=T \cdot b,
\end{aligned}
$$

where $a$ is the distance between two normal forces and $b$ is the distance between two frictional forces.

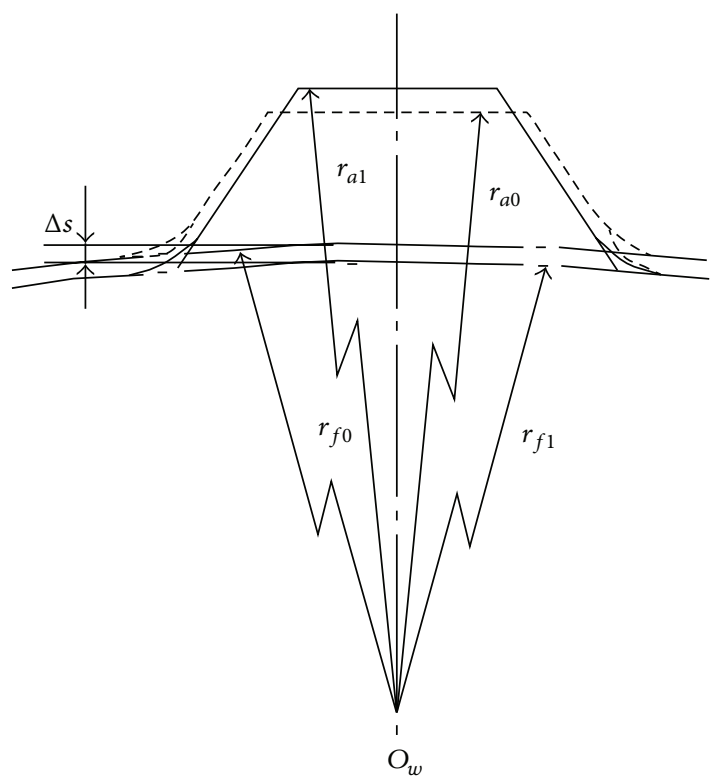

FIgURE 3: Sketch of decrement $\Delta s$.

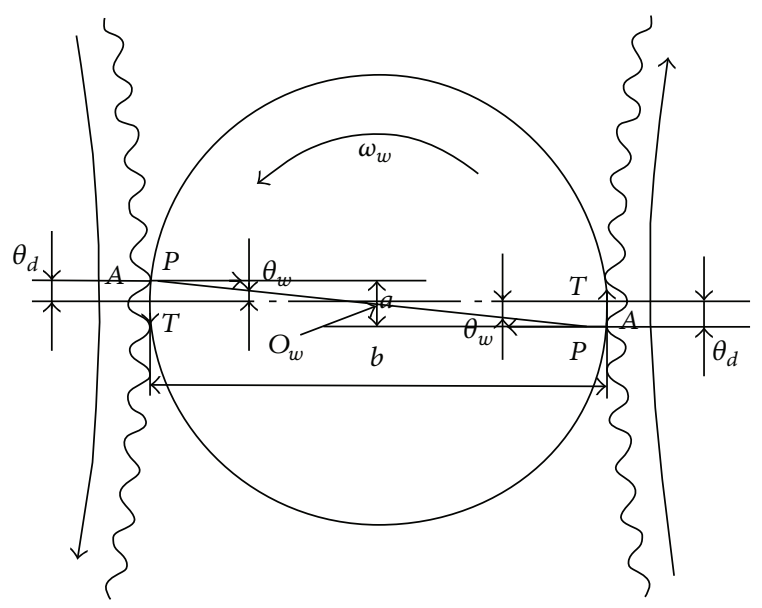

Figure 4: Force and moment arm.

Equation (5) can be obtained according to the geometrical relationship shown in Figure 4

$$
\frac{a}{2}=\left(\frac{d_{a_{d}}}{2}+\frac{d_{Z}}{2}-\Delta s\right) \sin \theta_{d}=\frac{d_{Z}}{2}(1+x-2 y) \sin \theta_{d} .
$$

Thus,

$$
a=d_{Z}(1+x-2 y) \sin \theta_{d} .
$$

Equation (7) can also be obtained according to the geometrical relationship

$$
\frac{b}{2}=\frac{d_{Z}}{2}\left[1+x\left(1-\frac{1}{\cos \theta_{d}}\right)-2 y\right] \cos \theta_{d} .
$$

$\theta_{d} \leq \pi / Z_{d}$, where $Z_{d}$ is the number of teeth for rolling die. In general, it should make $Z_{d}$ maximize according to 
the structure of rolling machine in industry, and the number is greater than 160 . Thus, the $\theta_{d}$ is small, and then (8) can be obtained:

$$
1-\frac{1}{\cos \theta_{d}} \approx 0
$$

Substituting (8) into (7), $b$ can expressed as follows:

$$
b=d_{Z}(1-2 y) \cos \theta_{d}
$$

Equation (10) can be obtained because $\theta_{d}$ is small:

$$
\tan \theta_{d} \approx \sin \theta_{d}
$$

Substituting (1), (4), (6), (9), and (10) into (2), then the following expression can be obtained:

$$
\mu \geq \frac{1+x-2 y}{1-2 y} \tan \theta_{d} \approx \frac{1+x-2 y}{1-2 y} \sin \theta_{d} .
$$

The central distance between billet and rolling die can be expressed as follows:

$$
\frac{d_{Z}}{2}(1+x-2 y)=\frac{d_{Z}}{2}\left(x \cos \theta_{d}+\cos \theta_{w}\right),
$$

where $\theta_{w}$ is the angle between $\overline{A O_{w}}$ and $\overline{O_{d} O_{w}}$. Here, $A$ is the center of contact area (i.e., line on the cross section), $O_{w}$ is the center of billet/workpiece, and $O_{d}$ is the center of die. The force line of $P$ also passes point $A$.

Equation (13) can be obtained according to the geometrical relationship shown in Figure 4:

$$
\frac{d_{a_{d}}}{2} \sin \theta_{d}=\frac{d_{Z}}{2} \sin \theta_{w} .
$$

Thus,

$$
\begin{gathered}
\sin \theta_{w}=\frac{d_{a_{d}}}{d_{Z}} \sin \theta_{d}=x \sin \theta_{d}, \\
\cos \theta_{w}=\sqrt{1-\sin ^{2} \theta_{w}}=\sqrt{1-x^{2} \sin ^{2} \theta_{d}} .
\end{gathered}
$$

Substituting (15) into (12), the following expression can be obtained:

$$
\cos \theta_{d}=1-\frac{2 y(1-y)}{x(1+x-2 y)} .
$$

The second and more than second order terms can be neglected because $y$ is small, and then $\sin \theta_{d}$ can be expressed as follows:

$$
\sin \theta_{d}=\sqrt{1-\cos ^{2} \theta_{d}}=\sqrt{\frac{4 y(1-y)}{x(1+x-2 y)}} .
$$

Substituting (17) into (11), the following expression can be obtained:

$$
\mu \geq \frac{1+x-2 y}{1-2 y} \sqrt{\frac{4 y(1-y)}{x(1+x-2 y)}} .
$$

Squaring both sides of (18) and neglecting second and more than second order terms, (19) can be obtained:

$$
\begin{gathered}
\mu^{2} \geq \frac{4 y+4 x y}{x-4 x y}=\frac{4 y(1+x)}{x-4 x y}>0, \\
\because 4 y(1+x)>0, \\
\therefore x-4 x y>0 .
\end{gathered}
$$

Thus, (21) can be obtained according to (19):

$$
y \leq \frac{1}{4} \cdot \frac{\mu^{2} x}{1+x+\mu^{2} x}=f_{1}(x) .
$$

3.2. Rotatory Condition in Rolling Process of Spline with Odd Number of Teeth. In rolling process of odd number of teeth spline, the forces are not symmetrical as shown in Figure 2. The Moments $M_{T}$ and $M_{P}$ can be expressed as follows:

$$
\begin{aligned}
& M_{P}=P_{L} a_{L}+P_{R} a_{R}, \\
& M_{T}=T_{L} b_{L}+T_{R} b_{R},
\end{aligned}
$$

where $a_{L}$ is the distance between center (point $O_{w}$ ) of billet and action line of $P_{L} ; a_{R}$ is the distance between center (point $O_{w}$ ) of billet and action line of $P_{R}$; and $b_{L}$ is the distance between center (point $O_{w}$ ) of billet and action line of $T_{L} ; b_{R}$ is the distance between center (point $O_{w}$ ) of billet and action line of $T_{R}$.

According to the geometrical relationship shown in Figure 2, the expressions of $a_{L}, a_{R}, b_{L}$, and $b_{R}$ can obtained

$$
\begin{gathered}
a_{L}=0, \\
a_{R}=\frac{d_{Z}}{2}(1+x-2 y) \sin \theta_{d}, \\
b_{L}=\frac{d_{Z}}{2}(1-2 y), \\
b_{R}=\frac{d_{Z}}{2}\left[1+x\left(1-\frac{1}{\cos \theta_{d}}\right)-2 y\right] \cos \theta_{d} .
\end{gathered}
$$

Substituting (8) into (26), $b_{R}$ can expressed as follows:

$$
b_{R}=\frac{d_{Z}}{2}(1-2 y) \cos \theta_{d} .
$$

At the initial rolling stage, the flank of workpiece has not been formed, and thus the contact is that between billet and addendum of rolling die, where the knuckle radius for addendum of rolling die is $r_{e}$. The contact between die and billet/workpiece is not continuous, and the situation of "contact-separate-contact" occurs. In the one rolling process which is from one tooth of die contacting to separating, the contact area between die and billet/workpiece fluctuates.

In the rolling process of spline with odd number of teeth, the contact state at left side is different from the contact state at right side. The forces are linear with respect to the contact area, so the forces at left side are also different from the forces at right side. Force parameters in rolling process of odd 
number of teeth spline are the double of force parameters in rolling process of even number of teeth spline. The moment arm parameters under odd number of teeth spline are also double of those under even number teeth spline. This brings difficulties to model rotatory condition. In order to reduce the parameters, the index $k$ has been introduced. The left contact area and right contact area are expressed as $S_{L}$ and $S_{R}$, respectively, and then the ratio of left forces to right forces can be expressed as follows:

$$
\frac{P_{L}}{P_{R}}=\frac{T_{L}}{T_{R}}=\frac{S_{L}}{S_{R}}=k
$$

Substituting (1), (22)-(25), (27), and (28) into (2), (29) can be obtained:

$$
\mu \geq \frac{1+x-2 y}{1-2 y} \cdot \frac{1}{\cos \theta_{d}+k} \cdot \sin \theta_{d} .
$$

Substituting (16) and (17) into (29), squaring both sides of (29), and neglecting second and more than second order terms, then the following expression can be obtained:

$$
\begin{aligned}
& \mu^{2} \geq\left(4 y(1+x)^{2}\right) \\
& \times\left((1+k)^{2}\left(x+x^{2}\right)\right. \\
& \left.\quad-2 y\left[2(1+k)+3(1+k)^{2} x+2(1+k)^{2} x^{2}\right]\right)^{-1}>0 \\
& \because 4 y(1+x)^{2}>0 \\
& \quad \therefore(1+k)^{2}\left(x+x^{2}\right) \\
& \quad-2 y\left[2(1+k)+3(1+k)^{2} x+2(1+k)^{2} x^{2}\right]>0 .
\end{aligned}
$$

Thus, (32) can be obtained according to (30)

$$
\begin{aligned}
y \leq & \frac{1}{2} \cdot\left(\mu^{2}(1+k)^{2}\left(x+x^{2}\right)\right) \\
& \quad \times\left(2(1+x)^{2}\right. \\
& \left.\quad+\mu^{2}\left[2(1+k)+3(1+k)^{2} x+2(1+k)^{2} x^{2}\right]\right)^{-1} \\
= & g(k) .
\end{aligned}
$$

\section{Results and Discussion}

4.1. Index $k$ for Odd Number of Teeth Spline. The mathematic model of contact area between billet/workpiece and addendum (knuckle radius region) of rolling die has been established by Zhang et al. [16]. At the forming stage concerned by this work, the flank of workpiece has not been formed and only addendum of rolling die contacts billet. Thus, the $S_{L}$ under the contact state shown in Figure 2 can be expressed as (33) according to the model established in [16]:

$$
S_{L}=r_{e} \arctan \frac{-\left(d_{Z} / 2\right) \cdot \sin \beta}{X_{e_{L}}-\left(d_{Z} / 2\right) \cdot \cos \beta},
$$

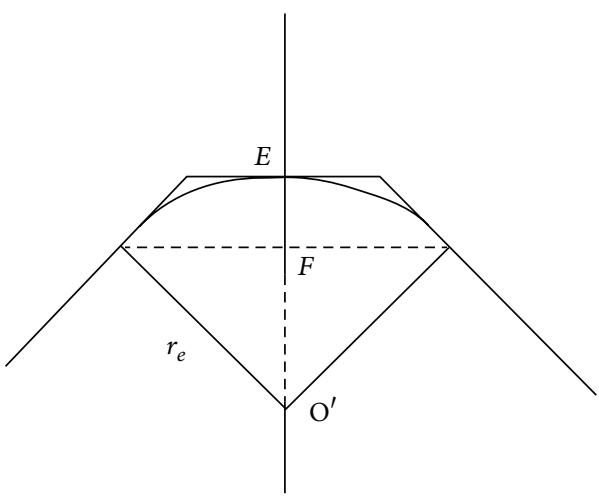

Figure 5: Geometry of addendum of rolling die.

where

$$
\begin{gathered}
r_{e}=\sec \alpha\left|\frac{d_{a_{d}}}{2} \tan \alpha-\frac{m Z_{d}}{2} \tan \alpha\right| \\
-\tan \alpha\left(\frac{d_{a_{d}}}{2} \tan \alpha-\frac{m Z_{d}}{2} \tan \alpha\right) \\
X_{e_{L}}=\frac{d_{Z}}{2}-\Delta s+r_{e} \\
\beta=-\arccos \frac{\left(d_{Z} / 2\right)^{2}+X_{e_{L}}^{2}-r_{e}^{2}}{d_{Z} X_{e_{L}}}
\end{gathered}
$$

where $r_{e}$ is the knuckle radius for addendum of rolling die, whose center is $O^{\prime}\left(X_{e}, Y_{e}\right)$, as shown in Figure 5; $\alpha$ is the pressure angle of reference circle; $m$ is the module of spline.

In the same way, the $S_{R}$ under the contact state shown in Figure 2 can be expressed as (37) according to the model established in [16]:

$$
\begin{aligned}
S_{R}=r_{e} & \left(\left|\arctan \frac{Y_{e_{R}}-\left(d_{Z} / 2\right) \cdot \sin \beta_{1}}{X_{e_{R}}-\left(d_{Z} / 2\right) \cdot \cos \beta_{1}}\right|\right. \\
& \left.+\left|\arctan \frac{Y_{e_{R}}-\left(d_{Z} / 2\right) \cdot \sin \beta_{2}}{X_{e_{R}}-\left(d_{Z} / 2\right) \cdot \cos \beta_{2}}\right|\right),
\end{aligned}
$$

where

$$
\begin{gathered}
X_{e_{R}}=\left(\frac{d_{a_{d}}}{2}+\frac{d_{Z}}{2}-\Delta s\right)-\left(\frac{d_{a_{d}}}{2}-r_{e}\right) \cos \left(-\theta_{d}\right), \\
Y_{e_{R}}=\left(\frac{d_{a_{d}}}{2}-r_{e}\right) \sin \left(-\theta_{d}\right), \\
\beta_{1}=-\arccos \frac{\left(d_{Z} / 2\right)^{2}+X_{e_{R}}^{2}+Y_{e_{R}}^{2}-r_{e}^{2}}{d_{Z} \sqrt{X_{e_{R}}^{2}+Y_{e_{R}}^{2}}} \\
+\arcsin \frac{Y_{e_{R}}}{\sqrt{X_{e_{R}}^{2}+Y_{e_{R}}^{2}}}
\end{gathered}
$$




$$
\begin{aligned}
\beta_{2}= & \arccos \frac{\left(d_{Z} / 2\right)^{2}+X_{e_{R}}^{2}+Y_{e_{R}}^{2}-r_{e}^{2}}{d_{Z} \sqrt{X_{e_{R}}^{2}+Y_{e_{R}}^{2}}} \\
& +\arcsin \frac{Y_{e_{R}}}{\sqrt{X_{e_{R}}^{2}+Y_{e_{R}}^{2}}} .
\end{aligned}
$$

Substituting (16) and (17) into (38), $X_{e_{R}}$ and $Y_{e_{R}}$ can be expressed as follows:

$$
\begin{gathered}
X_{e_{R}}=\frac{d_{Z}}{2}-\Delta s+r_{e}+\left(\frac{d_{a_{d}}}{2}-r_{e}\right) \frac{2 y(1-y)}{x(1+x-2 y)}, \\
Y_{e_{R}}=-\left(\frac{d_{a_{d}}}{2}-r_{e}\right) \sqrt{\frac{4 y(1-y)}{x(1+x-2 y)}} .
\end{gathered}
$$

Substituting (33) and (37) into (28), the index $k$ can be expressed as follows:

$$
\begin{aligned}
k= & \frac{S_{L}}{S_{R}}=\left(\arctan \frac{-\left(d_{Z} / 2\right) \cdot \sin \beta}{X_{e_{L}}-\left(d_{Z} / 2\right) \cdot \cos \beta}\right) \\
& \times\left(\left|\arctan \frac{Y_{e_{R}}-\left(d_{Z} / 2\right) \cdot \sin \beta_{1}}{X_{e_{R}}-\left(d_{Z} / 2\right) \cdot \cos \beta_{1}}\right|\right. \\
& \left.+\left|\arctan \frac{Y_{e_{R}}-\left(d_{Z} / 2\right) \cdot \sin \beta_{2}}{X_{e_{R}}-\left(d_{Z} / 2\right) \cdot \cos \beta_{2}}\right|\right)^{-1} \\
= & f\left(m, Z_{w}, Z_{d}, \alpha, \Delta s, h_{a}^{*}, h_{f}^{*}\right),
\end{aligned}
$$

where $Z_{w}$ is the number of spline/workpiece teeth; $h_{a}^{*}$ is the addendum coefficient of spline; $h_{f}^{*}$ is the dedendum coefficient of spline.

For standard spline, $h_{a}^{*}$ and $h_{f}^{*}$ change with the pressure angle; this can be found in the handbook. Thus, the present study is concerned with the influences of module, number of spline teeth, number of die teeth, decrement, and pressure angle on index $k$. The main parameters used in this work are listed in Table 1.

Figure 6 illustrates the index $k$ for different $Z_{w}$ and $Z_{d}$. It can be found from Figure 6(a) to Figure 6(c) that the changing trends of $k$ under different pressure angles are accordant. The diameter of rolling die is intimately associated with the $Z_{d}$. In general, $Z_{d}$ should be maximized according to the structure of rolling machine, and it is several times more than $Z_{w}$. The index $k$ increases sharply with increasing $Z_{w}$ but increases slightly with increasing $Z_{d}$, where the change of $k$ flattens out gradually after $Z_{w}=40-50$. The decrement $\Delta s$ can be chosen form $0.025 \mathrm{~mm}$ to $0.075 \mathrm{~mm}$ according to experience [16]. The $0.025 \mathrm{~mm}$ and $0.05 \mathrm{~mm}$ have been chosen in Figure 6 . It can be found that the decrement has a little influence on index $k$. The previous studies [16] indicated that the diameter of rolling die and decrement also have a little influence on contact area.

Figure 7 illustrates the index $k$ for different modules and pressure angles. It can be seen from Figure 7 that index $k$ decreases with the increase in module, but it has slight variations. The pressure angle has a notable influence on the index $k$, but the degree of influence by $\alpha$ is less than by $Z_{w}$. The $Z_{w}$ is the main factor to effect index $k$, and the fluctuation for value of $k$ is less than 1 when $Z_{w}$ is a constant. In general, range of index $k$ is 1 to 5 for standard circular-dedendum spline in China; that is,

$$
1<k<5
$$

4.2. Comparison of Rotatory Condition. The rotatory condition for rolling process of spline with even number of teeth is very different from that with odd number of teeth, and the rotatory condition under odd number of teeth is very complex. Thus, it is necessary to simplify the expression of rotatory condition under odd number of teeth and to compare the rotatory condition between even and odd number of teeth.

Letting

$$
g(k)=\frac{1}{2} \cdot \frac{u_{1}(k)}{u_{2}(k)}
$$

where

$$
\begin{gathered}
u_{1}(k)=\mu^{2}(1+k)^{2}\left(x+x^{2}\right), \\
u_{2}(k)=2(1+x)^{2} \\
+\mu^{2}\left[2(1+k)+3(1+k)^{2} x+2(1+k)^{2} x^{2}\right],
\end{gathered}
$$

thus

$$
\begin{aligned}
g^{\prime}(k) & =\frac{1}{2} \cdot \frac{u_{1}{ }^{\prime}(k) u_{2}(k)-u_{1}(k) u_{2}{ }^{\prime}(k)}{\left[u_{2}(k)\right]^{2}} \\
& =\frac{\mu^{2}(1+k)\left(x+x^{2}\right)\left[2(1+x)^{2}+\mu^{2}(1+k)\right]}{\left[u_{2}(k)\right]^{2}} \\
& \because \mu>0, k>0, x>0 \\
\therefore g^{\prime}(k) & =\frac{\mu^{2}(1+k)\left(x+x^{2}\right)\left[2(1+x)^{2}+\mu^{2}(1+k)\right]}{\left[u_{1}(k)\right]^{2}} \\
& >0 .
\end{aligned}
$$

So the $g(k)$ is a monotonically increasing function of $k$. Combining (42), (32) can be expressed as follows:

$$
y \leq g(1)<g(k) .
$$

Thus, the rotatory condition under odd number of teeth can be expressed as follows:

$$
y \leq g(1)=\frac{\mu^{2} x(1+x)}{(1+x)^{2}+2 \mu^{2}\left(1+3 x+2 x^{2}\right)}=f_{2}(x) .
$$

The ratio of the right side of (21) (rotatory condition under even number of teeth) to the right side of (48) 
TABLE 1: Parameters of standard circular-dedendum spline in China [17].

\begin{tabular}{lcccc}
\hline Pressure angle & Addendum coefficient Dedendum coefficient & Module & $m(\mathrm{~mm})$ & $\begin{array}{c}\text { Number of spline } \\
\text { teeth } \\
\alpha\left(^{\circ}\right)\end{array}$ \\
\hline 30 & $h_{a}^{*}$ & $h_{f}^{*}$ & 0.9 & $0.5,(0.75), 1,(1.25), 1.5,(1.75), 2,2.5,3,(4), 5,(6),(8), 10$ \\
37.5 & 0.5 & 0.7 & $0.25,0.5,(0.75), 1,(1.25), 1.5,(1.75), 2,2.5$ & $Z_{w}$ \\
45 & 0.45 & 0.6 & 0.4 & $10 \sim 100$ \\
\hline
\end{tabular}

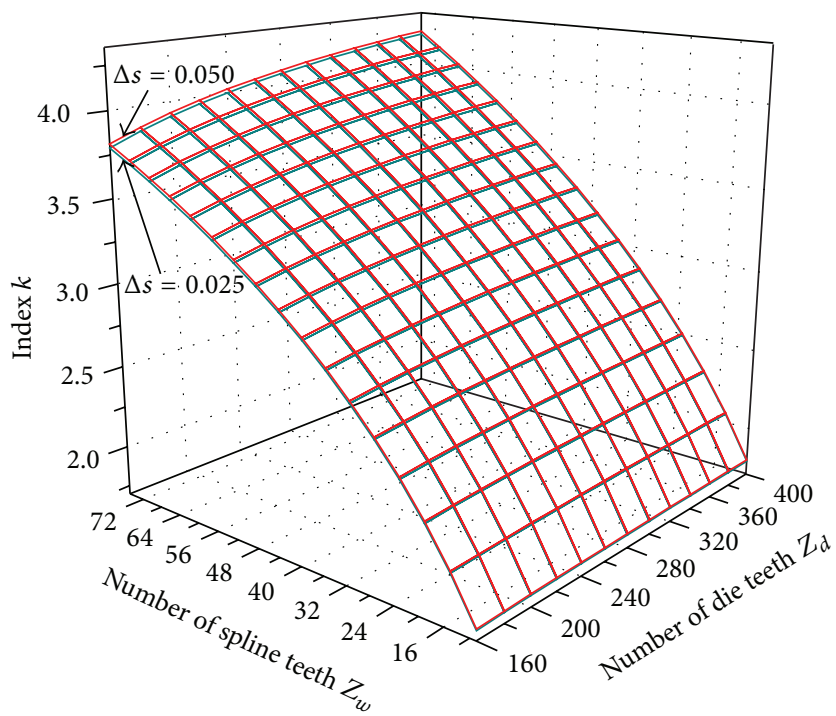

(a)

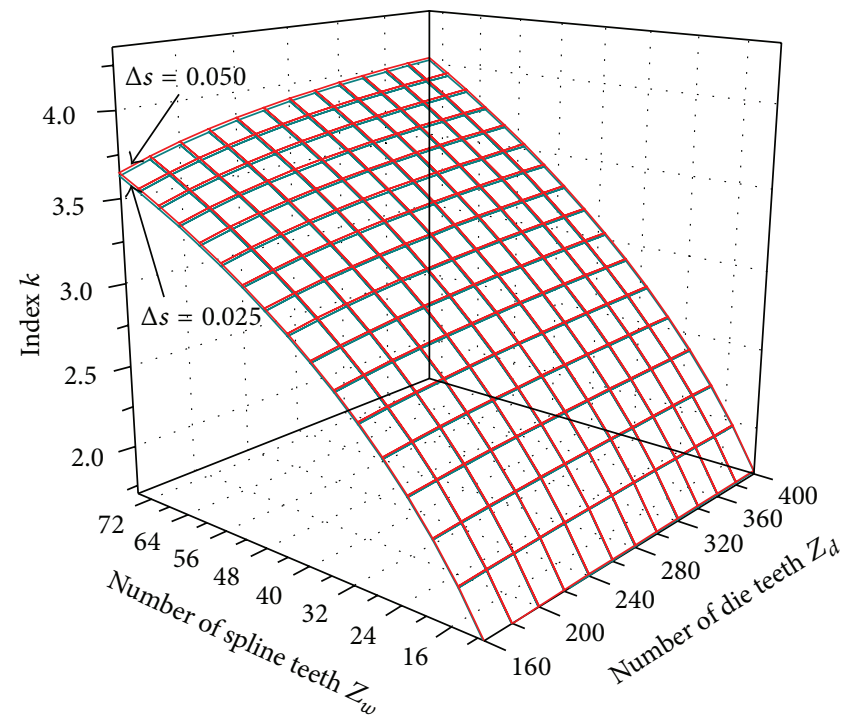

(b)

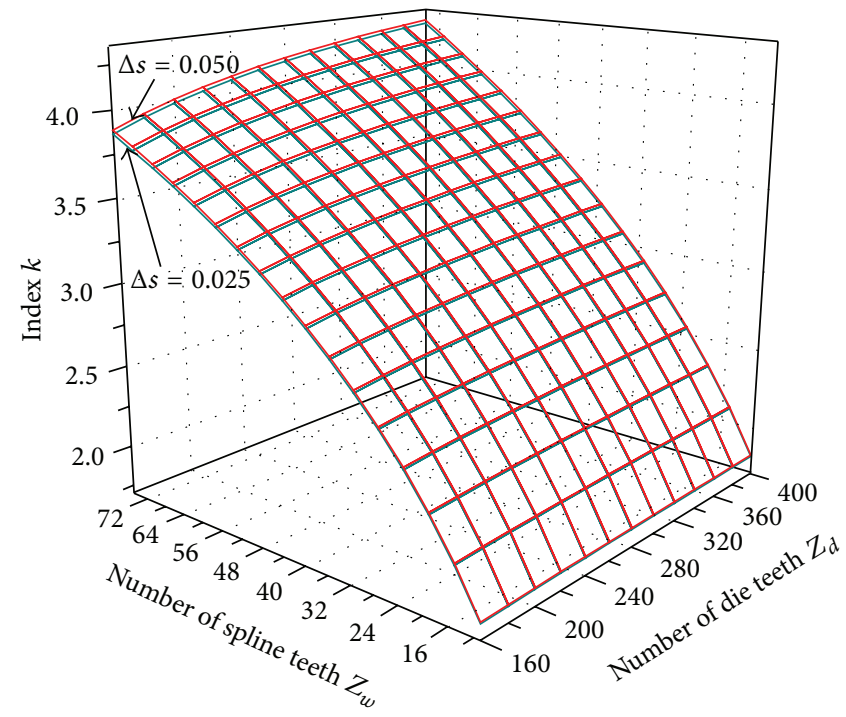

(c)

Figure 6: Value of the index $k$ by different tooth numbers for spline and die: (a) $\alpha=30^{\circ}$, (b) $\alpha=37.5^{\circ}$, and (c) $\alpha=45^{\circ}$.

(rotatory condition under odd number of teeth) can be expressed as follows:

$$
f_{3}(x)=\frac{f_{1}(x)}{f_{2}(x)}=\frac{1}{4} \cdot \frac{(1+x)^{2}+2 \mu^{2}\left(1+3 x+2 x^{2}\right)}{(1+x)\left(1+x+\mu^{2} x\right)} .
$$

In the same way (deducing $g^{\prime}(k)$ ), the first derivative of $f_{3}(x)$ can be obtained:

$$
f_{3}^{\prime}(x)=\frac{1}{4} \cdot \frac{\mu^{2}\left(1-2 \mu^{2}\right)}{\left(1+x+\mu^{2} x\right)^{2}} .
$$




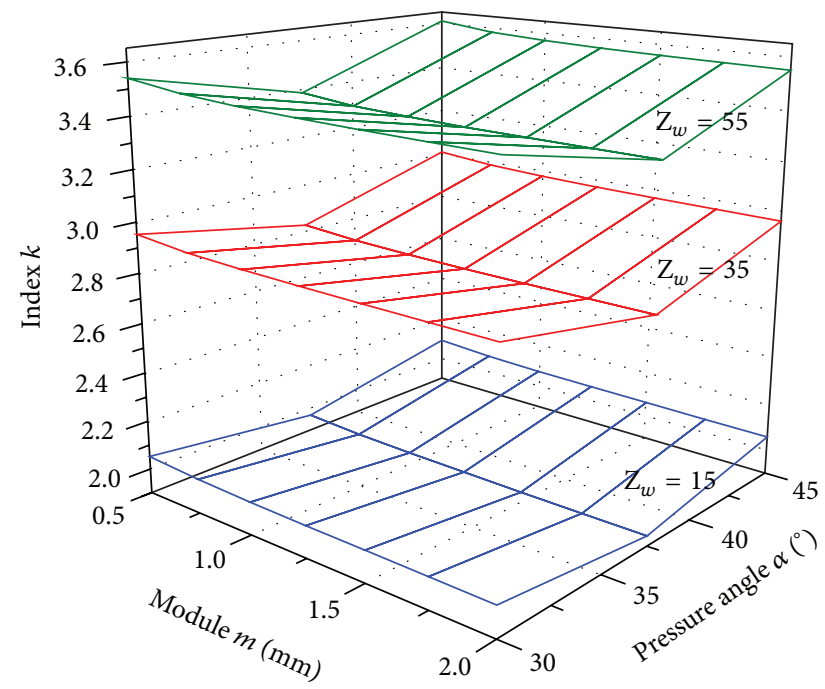

Figure 7: Value of the index $k$ by different $m$ and $\alpha$.

The maximum value of friction coefficient is 0.577 based on Von Mises yielding criteria; that is, $\mu_{\max }=0.577[18,19]$. Thus, (51) can be obtained

$$
1-2 \mu^{2}>0
$$

Substituting (51) into (50), then

$$
f_{3}^{\prime}(x)>0 \text {. }
$$

So the $f_{3}(x)$ is a monotonically increasing function of $x$. Generally, $x$ is greater than 1 in industry, but it would not be too large due to restriction of structure of rolling machine, and its maximum value is less than 10-15. Thus,

$$
f_{3}(x) \leq f_{3}(15)=\frac{64+248 \mu^{2}}{256+240 \mu^{2}}=h(\mu) .
$$

In the same way (deducing $g^{\prime}(k)$ ), the first derivative of $h(\mu)$ can be obtained

$$
h^{\prime}(\mu)=\frac{96256 \mu}{\left(256+240 \mu^{2}\right)^{2}}>0 .
$$
Then

So the $h(\mu)$ is a monotonically increasing function of $\mu$.

$$
h(u) \leq h(0.577)=0.4363 .
$$

Considering $f_{1}(x)>0, f_{2}(x)>0$ and (49)-(55), it is found that the rotatory condition under odd number of teeth is superior to the rotatory condition under even number of teeth. In other word, if $x, y$, and $\mu$ satisfy the rotatory condition for rolling process of even number of teeth spline, then they also satisfy the rotatory condition for rolling process of odd number of teeth spline; but the converse is not always true. The practice also indicated that the rolling forming quality of odd number teeth spline $\left(Z_{w}=29\right)$ is much better than the forming quality of even number teeth spline $\left(Z_{w}=28\right)[4]$.
4.3. Application of Rotatory Condition. According to (21), the maximum $\left(y_{\max }\right)$ of relative decrement in rolling process of even number of teeth spline can be expressed as

$$
y_{\max }=\frac{1}{4} \cdot \frac{\mu^{2} x}{1+x+\mu^{2} x} .
$$

According to (48), the maximum ( $\left.y_{\max }\right)$ of relative decrement in rolling process of odd number teeth spline can be expressed as

$$
y_{\max }=\frac{\mu^{2} x(1+x)}{(1+x)^{2}+2 \mu^{2}\left(1+3 x+2 x^{2}\right)} .
$$

The curves for maximal relative decrement can be plotted according to (56) and (57), as shown in Figure 8. The changing trends under even number of teeth and under odd number of teeth are accordant, although the values are different. It can be seen from Figure 8 that the friction coefficient has a notable influence on the rotatory condition. In rotatory condition for simple cross rolling, the friction coefficient also plays an important role.

It can be found from Figure 8 that the ratio $(x)$ of outside diameter of rolling die to diameter of billet before rolling has little influence on maximum $\left(y_{\max }\right)$ of relative decrement, when $x>5$; but $y_{\max }$ decreases sharply with decreasing $x$, when $x<5$; especially $x<3$. The friction is larger, and this tendency is more notable.

Figure 9 illustrates the increased percent for maximal relative decrement when $x$ increases to 15 . The maximal relative decrement $y_{\max }$ increases $10 \%$, when $x$ increases from 5 to 15 ; and the maximal relative decrement $y_{\max }$ increases $5 \%$, when $x$ increases from 9 to 15. Thus, the outside diameter of rolling die should be five times greater than the diameter of billet before rolling in the interest of rotatory condition. In the practice, the ratio of $Z_{d}$ to $Z_{w}$ can be adopted instead of $x$; that is, $Z_{d} / Z_{w}>5$.

Based on the rotatory condition, the decrement $\Delta s$ can be expressed as follows:

$$
\begin{gathered}
\Delta s=y d_{Z}, \\
\Delta s \leq y_{\max } d_{Z} .
\end{gathered}
$$

The decrement is determined by angular velocity $\omega_{d}$ and infeeding speed $v$. The rotatory condition is better when the friction and the ratio of diameter of die to diameter of workpiece are large, that is, larger maximal relative decrement $y_{\max }$. Then the range for available decrement is large, so the adjustable range of parameters enlarges.

The density variation before rolling and after rolling is very small, and the deformation in the axial direction only occurring in local area for the end of billet can be neglected, so the diameter $\left(d_{Z}\right)$ of billet before rolling can be determined according to volume constancy principle. $d_{Z}$ can be calculated by

$$
d_{Z}=\sqrt{d_{f_{w}}^{2}+\frac{4}{\pi} A_{\text {tooth }} \cdot Z_{w}}
$$




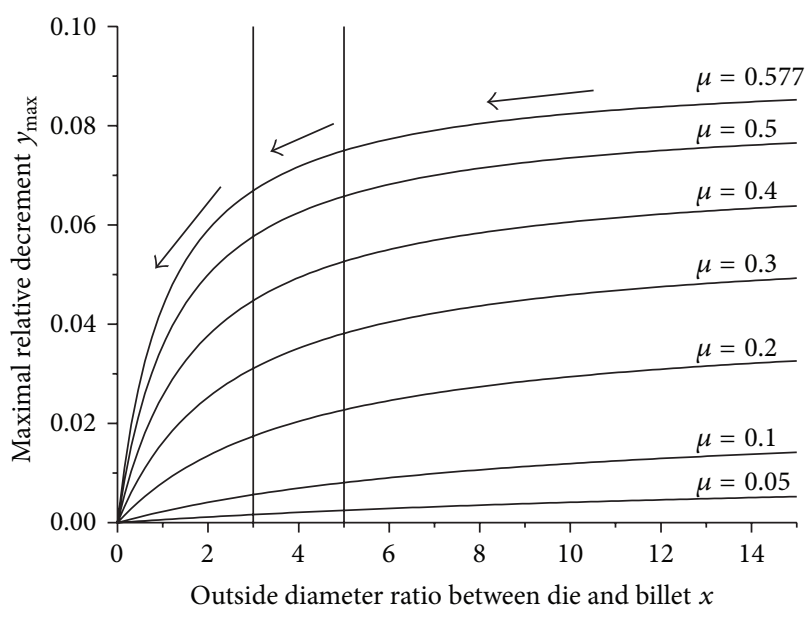

(a)

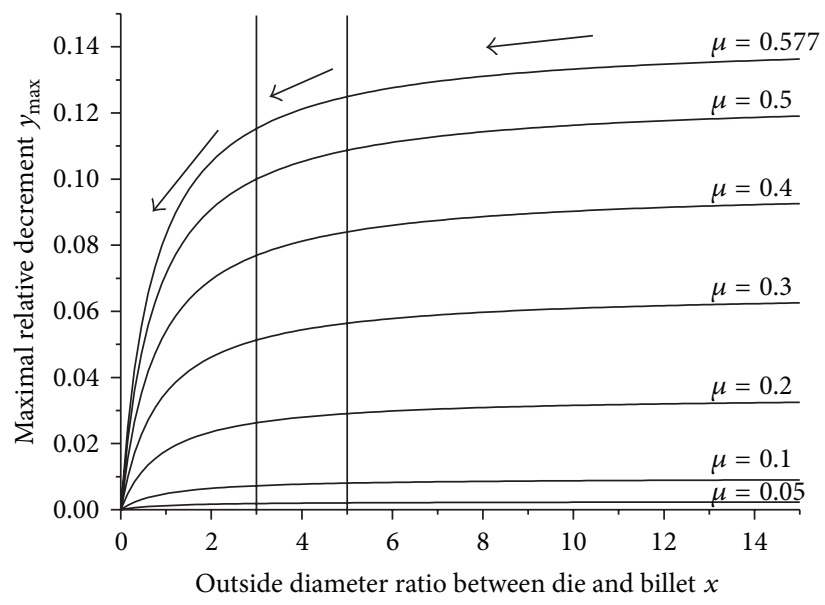

(b)

Figure 8: Maximal relative decrement: (a) even number of teeth; (b) odd number of teeth.

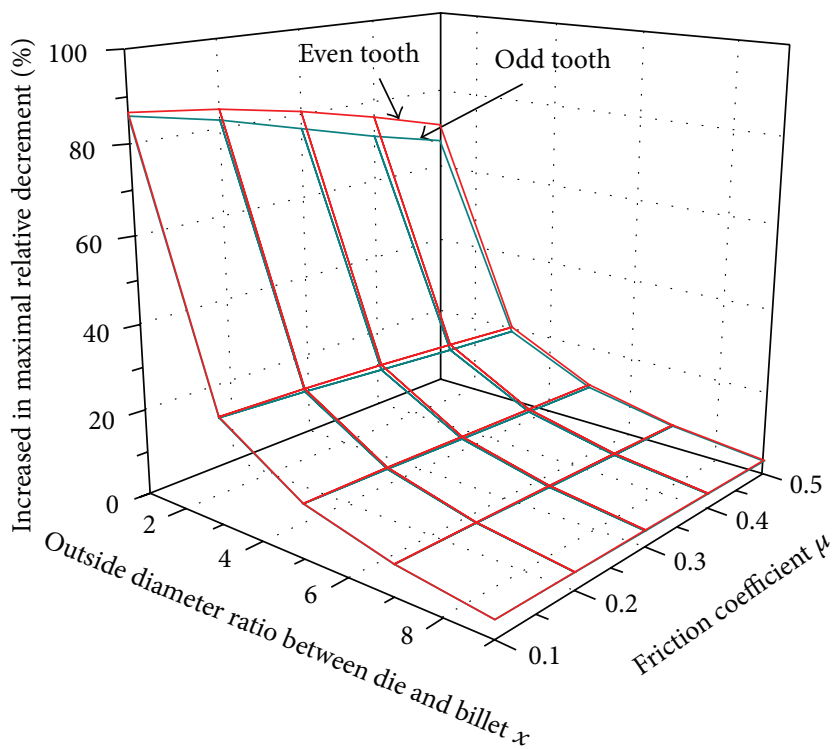

Figure 9: Percent of change for maximal relative decrement.

where $d_{f_{w}}$ is the root diameter of spline and $A_{\text {tooth }}$ is the area between tip circle and root circle for one tooth.

Equation (58) describes the available range of decrement which can satisfy the rotatory condition. However, the decrement is also restricted by the geometry of die besides the rotatory condition. According to the addendum structure of rolling die shown in Figure 5, the decrement should be less than chord height $\overline{E F}$; that is,

$$
\Delta s \leq \overline{E F},
$$

where

$$
\overline{E F} \approx r_{e}\left[1-\sin \left(\alpha-\frac{\pi}{2 Z_{d}}\right)\right] .
$$

Equation (60) describes the available range of decrement which is determined by geometry of die. To determine the decrement one must comprehensively consider rotatory condition and geometry of die. Thus, the decrement is determined by (58) and (60) according to specific processing parameters, as shown in Figure 10.

It can be found from Figure 10 that, for the rolling process of even number teeth spline, the available range of decrement determined by rotatory condition (58) is smaller than that determined by geometry of die (60); but for the rolling process of odd number teeth spline, the available range of decrement determined by rotatory condition (58) is larger than that determined by geometry of die (60), when $x>3$. The range of available decrement considering rotatory condition and geometry of die under odd number of teeth is larger than that under even number (near the odd number) of teeth. Thus, the decrement can be determined by (21), which can satisfy the needs for rotatory condition and geometry of die.

\section{Conclusions}

(1) Based on rotatory condition for simple cross rolling, the rotatory condition for spline rolling has been established according to the forming characteristic of spline rolling. The changing trends of rotatory condition under even number of teeth and under odd number of teeth are accordant, although the expressions are different. However, the rotatory condition under odd number of teeth is superior to that under even number of teeth.

(2) The range of decrement satisfying rotatory condition reduces quickly when the outside diameter ratio $(x)$ between die and billet decreases to less than five, especially under high friction condition. In the spline rolling process, the outside diameter ratio should be greater than five, and the teeth ratio $\left(Z_{d} / Z_{w}\right)$ between die and workpiece can be adopted instead of the outside diameter ratio.

(3) Available decrement is determined by considering rotatory condition (58) and geometry of die (60). 


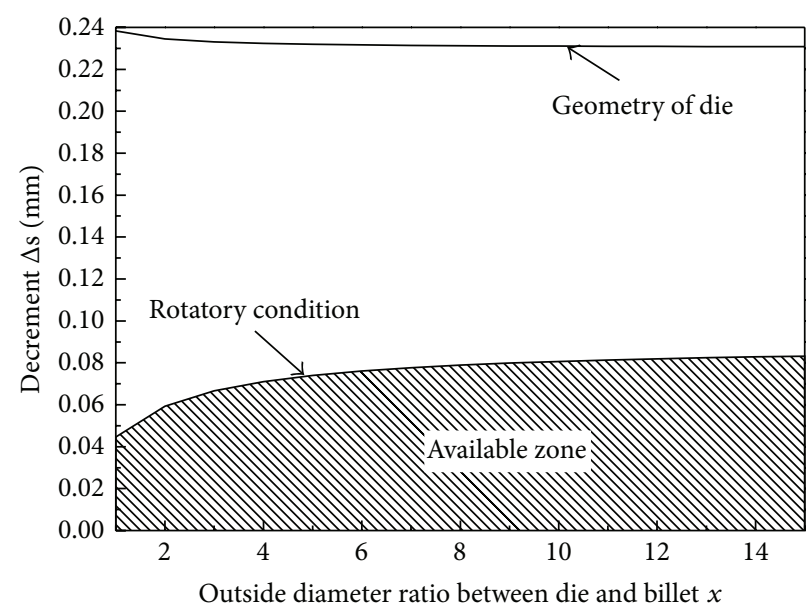

(a)

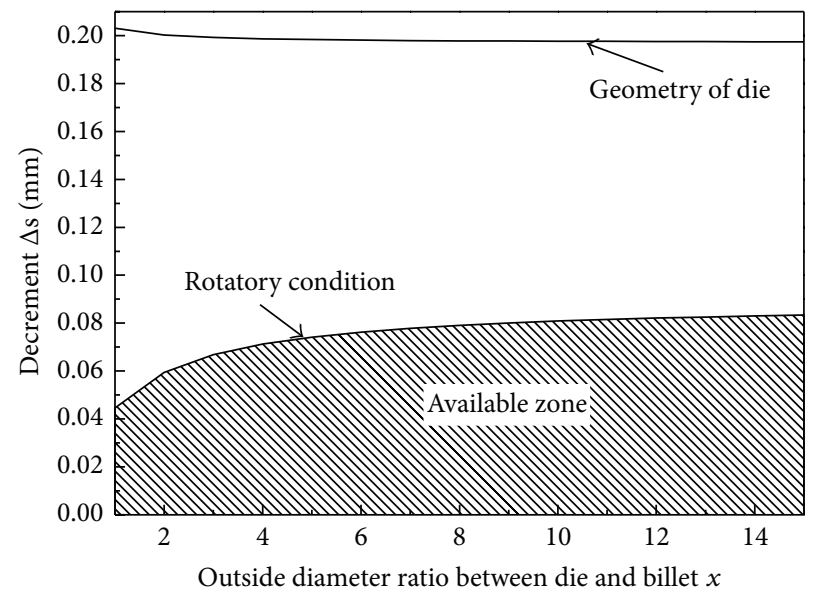

(c)

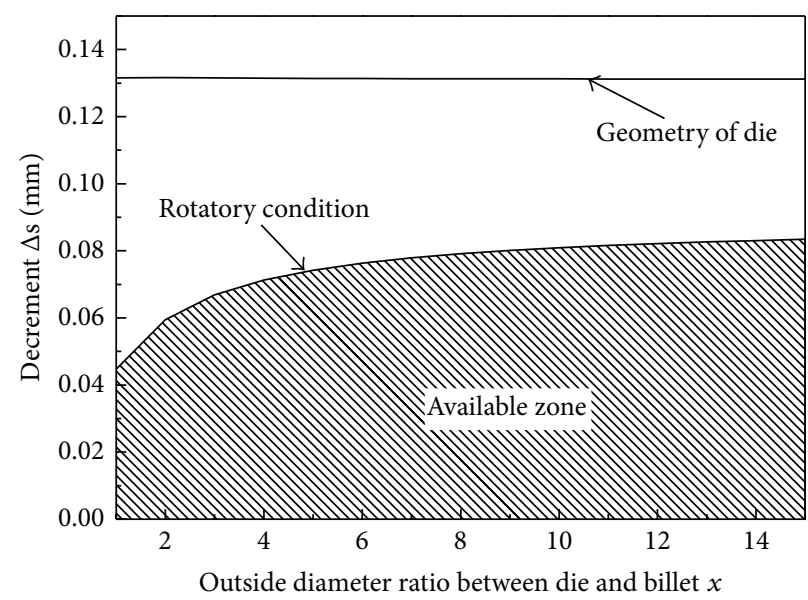

(e)

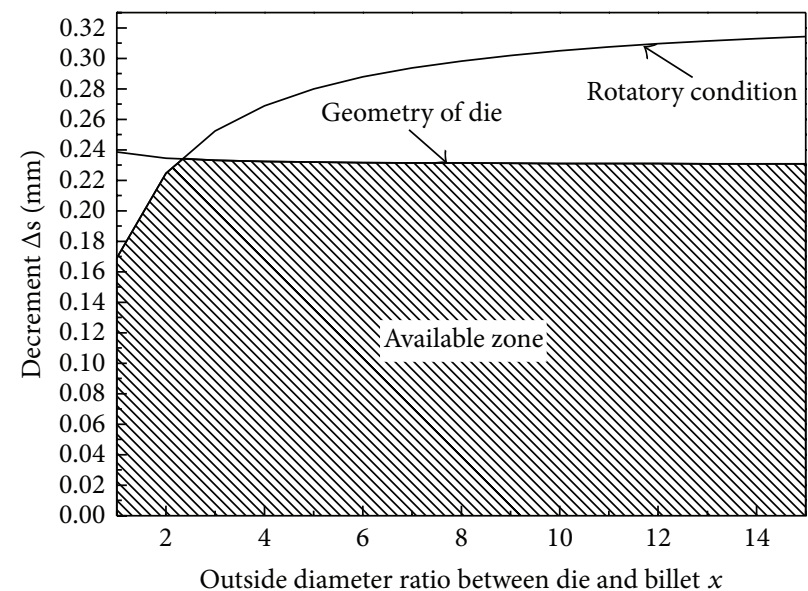

(b)

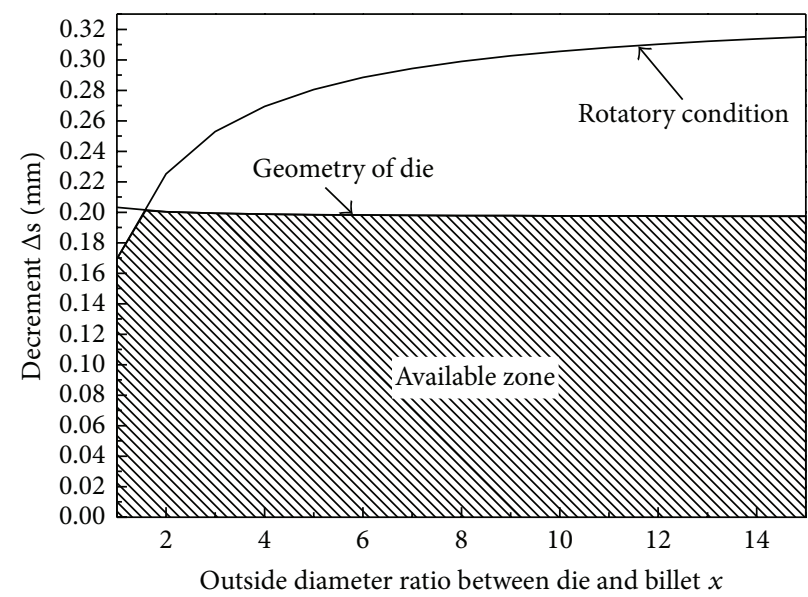

(d)

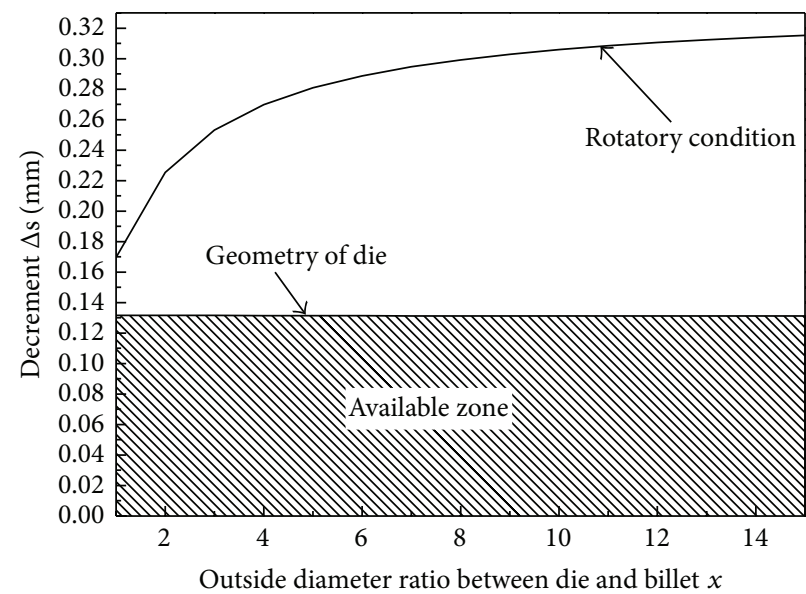

(f)

Figure 10: Selecting range of decrement: (a) $\alpha=30^{\circ}, Z_{w}=36$; (b) $\alpha=30^{\circ}, Z_{w}=35$; (c) $\alpha=37.5^{\circ}, Z_{w}=36$; (d) $\alpha=37.5^{\circ}, Z_{w}=35$; (e) $\alpha=45^{\circ}, Z_{w}=36$; and (f) $\alpha=45^{\circ}, Z_{w}=35$. 
In general, the maximal decrement determined by rotatory condition is smaller than that by geometry of die under even number of teeth, but it is on the contrary under odd number of teeth. The range of available decrement considering both aspects under odd number of teeth is larger than that under the neighbor even number of teeth.

\section{Appendix}

See Table 1.

\section{Nomenclatures}

A:

$A_{\text {tooth }}$ :

$a, a_{L}, a_{R}$ :

$b, b_{L}, b_{R}$ :

$d_{a_{d}}$ :

$d_{f_{w}}$ :

$d_{Z}$ :

$E, F$ :

$f_{1}(x), f_{2}(x), f_{3}(x)$ :

$g(k), u_{1}(k), u_{2}(k)$ :

$h(\mu)$ :

$h_{a}^{*}:$

$h_{f}^{*}$ :

$k:$

$m:$

$M_{P}$ :

$M_{T}$ :

$\mathrm{O}^{\prime}$ :

$O_{d}$ :

$\mathrm{O}_{w}$ :

$P, P_{L}, P_{R}$ :

$r_{a 0}$ :

$r_{a 1}$ :

$r_{e}:$

$r_{f 0}:$

$r_{f 1}:$

$S_{L}$ :

$S_{R}$ :

$T, T_{L}, T_{R}$ :

$v$ :

$x$ :

$X_{e}, X_{e_{L}}, X_{e_{R}}$ :

$y$ :

$Y_{e}, Y_{e_{L}}, Y_{e_{R}}$ :

$y_{\max }$ :
Center of contact area (i.e., line on the cross section)

Area between tip circle and root circle for one tooth of spline Moment arm of normal force Moment arm of frictional force Outside diameter of rolling die Root diameter of spline Initial diameter of billet End points of chord height

Function of $x$

Function of $k$

Function of $\mu$

Addendum coefficient of spline Dedendum coefficient of spline Index parameter Module of spline

Moment of normal forces Moment of frictional forces Center of the knuckle radius for addendum of rolling die Center of die Center of billet/workpiece Normal force Tip radius of billet/workpiece before one tooth of die contacting Tip radius of billet/workpiece after one tooth of die separating Knuckle radius for addendum of rolling die

Root radius of billet/workpiece before one tooth of die contacting Root radius of billet/workpiece after one tooth of die separating Left contact area

Right contact area

Frictional force

Infeeding speed of rolling die Outside diameter ratio between die and billet

Coordinate of $x$ axis

Relative decrement

Coordinate of $y$ axis

Maximal relative decrement
$Z_{d}: \quad$ Number of rolling die teeth

$Z_{w}$ : Number of spline/workpiece teeth

$\alpha: \quad$ Pressure angle of reference circle

$\beta, \beta_{1}, \beta_{2}$ : Angle parameters

$\Delta s: \quad$ Decrement

$\theta_{d}: \quad$ Angle between $\overline{O_{d} A}$ and $\overline{O_{d} O_{w}}$

$\theta_{w}: \quad$ Angle between $\overline{A O_{w}}$ and $\overline{O_{d} O_{w}}$

$\pi$ : $\quad$ Ratio of a circle's circumference to its diameter

$\mu: \quad$ Friction coefficient

$\omega_{d}$ : Angular velocity of rolling die

$\omega_{w}$ : Angular velocity of billet/workpiece.

\section{Conflict of Interests}

The authors declare that there is no conflict of interests regarding the publication of this paper.

\section{Acknowledgments}

The authors would like to gratefully acknowledge the supports of the National Natural Science Foundation of China (Grant no. 51305334), National Natural Science Foundation of China for key program (Grant no. 51335009), China Postdoctoral Science Foundation (Grant no. 2013M530420), and Fundamental Research Funds for the Central Universities (Grant no. XJJ2013035).

\section{References}

[1] R. Neugebauer, D. Klug, and U. Hellfritzsch, "Description of the interactions during gear rolling as basis for method for the prognosis of the attainable quality parameters," Production Engineering Research and Development, vol. 1, no. 3, pp. 253-257, 2007.

[2] D. Zhang, Y. Li, J. Fu, and Q. Zheng, "Mechanics analysis on precise forming process of external spline cold rolling," Chinese Journal of Mechanical Engineering, vol. 20, no. 3, pp. 54-58, 2007.

[3] R. Neugebauer, U. Hellfritzsch, and M. Lahl, "Advanced process limits by rolling of helical gears," International Journal of Material Forming, vol. 1, no. 1, supplement, pp. 1183-1186, 2008.

[4] J. F. Shen, "Selected spline tooth number with processing large pressure angle involute alpine by cold rotary rolling," New Technology and New Process, no. 2, pp. 41-42, 2004 (Chinese).

[5] H. Tschätsch, Metal Forming Practise, Springer, Berlin, Germany, 2006, Translated by A. Koth.

[6] D. Zhang, Y. Li, J. Fu, and Q. Zheng, "Rolling force and rolling moment in spline cold rolling using slip-line field method," Chinese Journal of Mechanical Engineering, vol. 22, no. 5, pp. 688-695, 2009.

[7] Z. H. Hu, K. S. Zhang, B. Y. Wang, X. D. Shu, and C. P. Yang, Forming Technology and Simulation for Parts by Cross Wedge Rolling, Metallurgic Industry Press, Beijing, China, 2005 (Chinese).

[8] D. W. Zhang, Theoretical research on process of spline cold rolling [M.S. thesis], Taiyuan University of Science and Technology, Shanxi, China, 2007 (Chinese).

[9] J. Bartnicki and Z. Pater, "The aspects of stability in crosswedge rolling processes of hollowed shafts," Journal of Materials Processing Technology, vol. 155-156, no. 1-3, pp. 1867-1873, 2004. 
[10] R. Nastunaga, T. Takemasu, T. Ozaki, H. Miyahara, R. Kamashita, and H. Tsukamoto, "Spline rolling of deep drawn cups," in Proceedings of the 6th International Conference on Technology of Plasticity (ICTP '99), pp. 2431-2436, Springer, Nuremberg, Germany, September 1999.

[11] Z. Q. Liu, J. L. Song, H. P. Qi, Y. T. Li, and X. D. Li, "Parameters and experiments on the precision forming process of spline cold rolling," Applied Mechanics and Materials, vol. 34-35, pp. 646650, 2010.

[12] A. A. Kamouneh, J. Ni, D. Stephenson, and R. Vriesen, "Investigation of work hardening of flat-rolled helical-involute gears through grain-flow analysis, FE-modeling, and strain signature," International Journal of Machine Tools and Manufacture, vol. 47, no. 7-8, pp. 1285-1291, 2007.

[13] Y. Y. Li and S. D. Zhao, "Study on the improvements of incremental rolling process for spline shaft with round tools based on finite element method," in Proceedings of the IEEE International Conference on Mechatronics and Automation, pp. 98-103, Kagawa, Japan, 2013.

[14] J. Kretzschmar, M. Stockmann, J. Ihlemann, S. Schiller, and U. Hellfritzch, "Experimental-numerical investigation of the rolling process of high gears," Experimental Techniques, 2013.

[15] Z. K. Wang and Q. Zhang, "Numerical simulation of involutes spline shaft in cold rolling forming," Journal of Central South University of Technology, vol. 15, no. 2, supplement, pp. 278-283, 2008.

[16] D. W. Zhang, Y. T. Li, and J. H. Fu, "Theoretical calculation and simulation analysis on rolling contact area of external spline cold rolling," Journal of Taiyuan University of Science and Technology, vol. 28, no. 1, pp. 64-68, 2007 (Chinese).

[17] Z. P. Zhan, B. Y. Chang, and C. X. Ming, Involute Spline Standards Application Manual, Standards Press of China, Beijing, China, 1997 (Chinese).

[18] D.-K. Leu, "A simple dry friction model for metal forming process," Journal of Materials Processing Technology, vol. 209, no. 5, pp. 2361-2368, 2009.

[19] E. Ghassemali, M. J. Tan, A. E. W. Jarfors, and S. C. V. Lim, "Progressive microforming process: towards the mass production of micro-parts using sheet metal," International Journal of Advanced Manufacturing Technology, vol. 66, no. 5-8, pp. 611-621, 2013. 


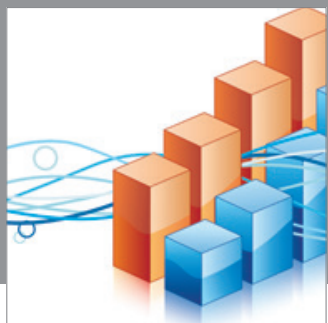

Advances in

Operations Research

mansans

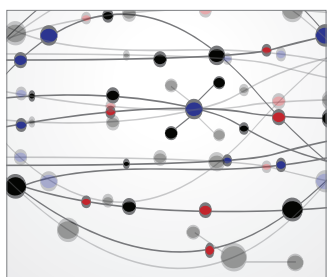

The Scientific World Journal
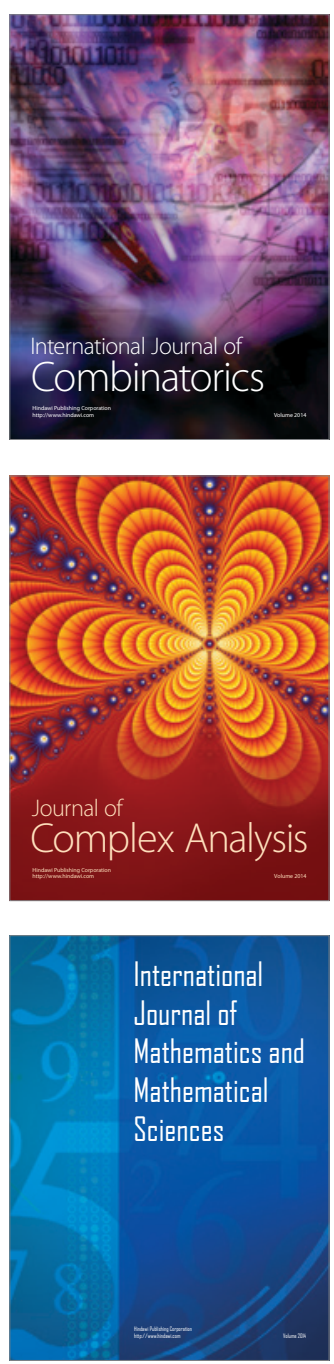
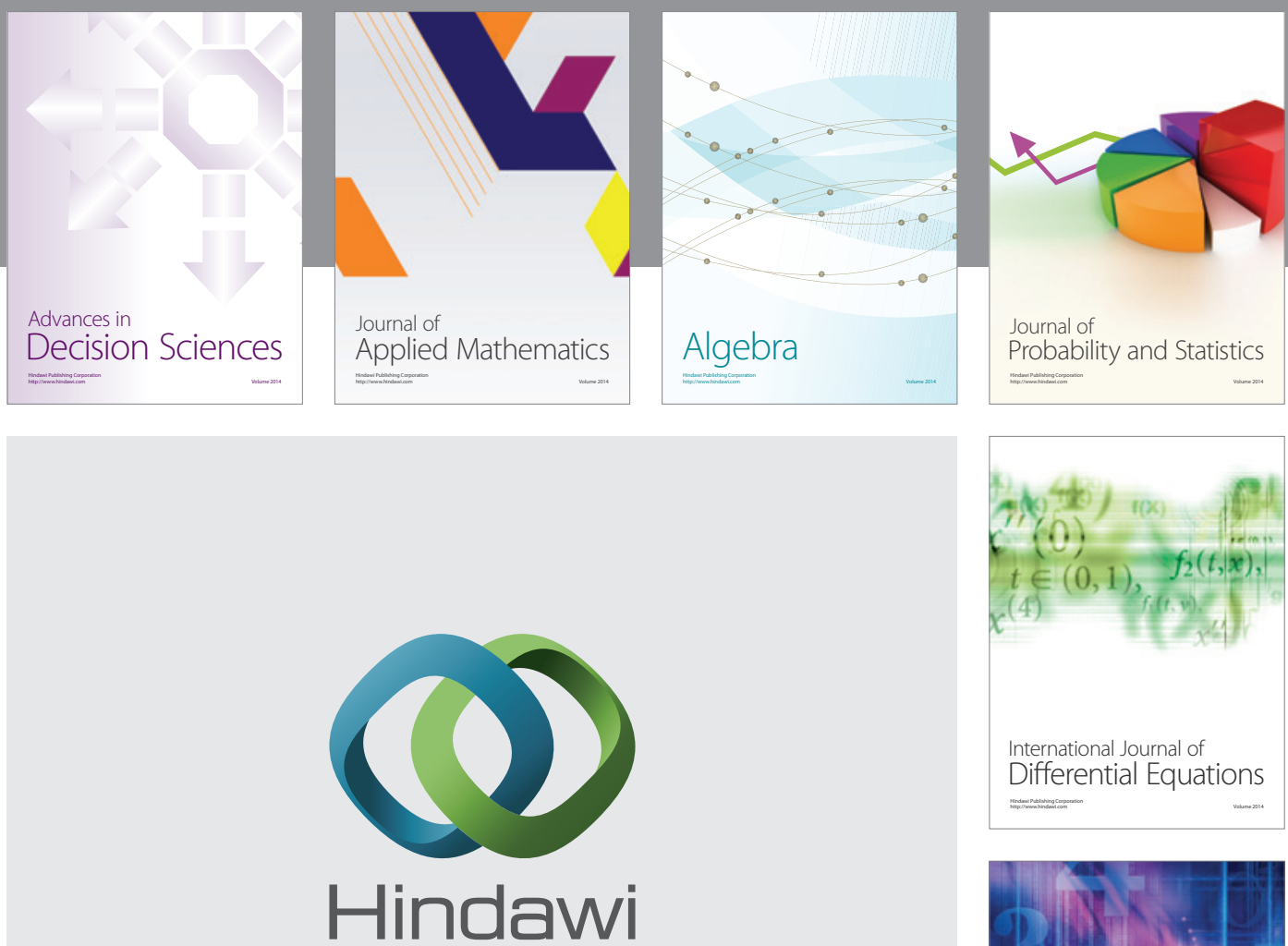

Submit your manuscripts at http://www.hindawi.com
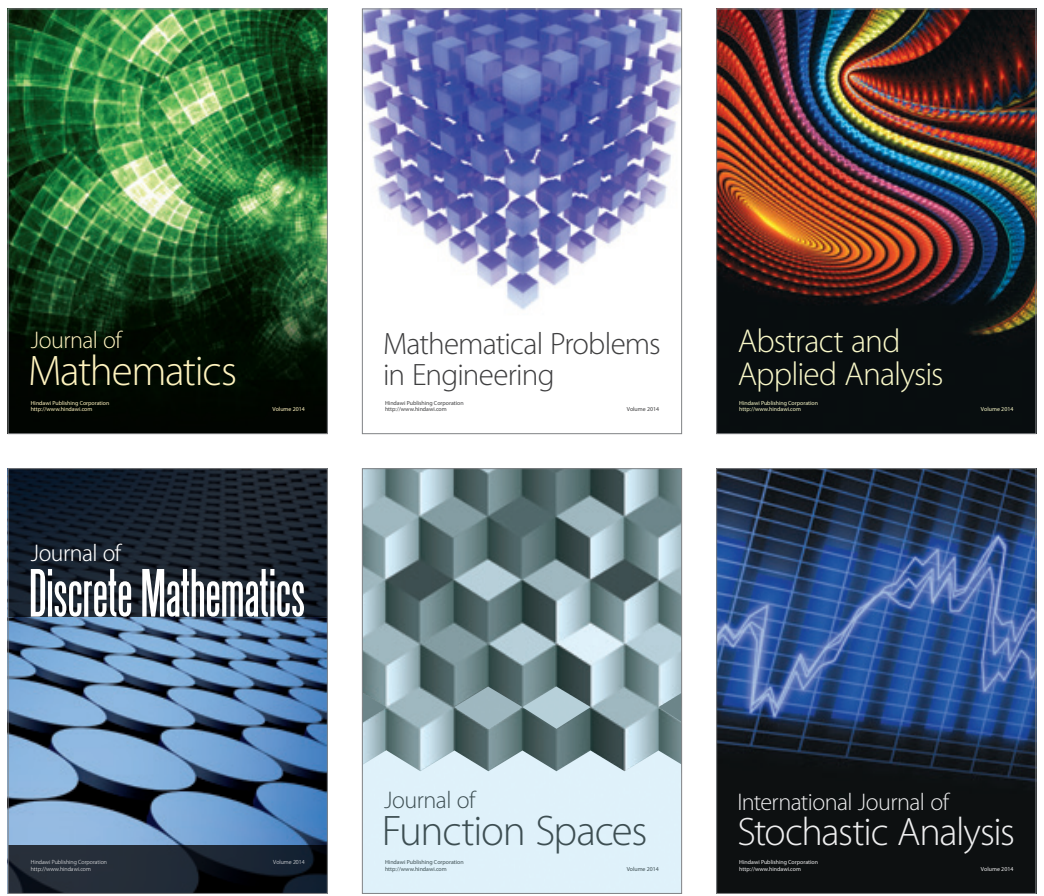

Journal of

Function Spaces

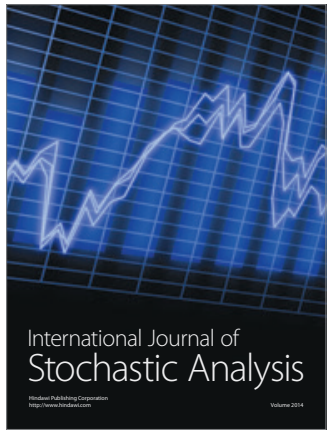

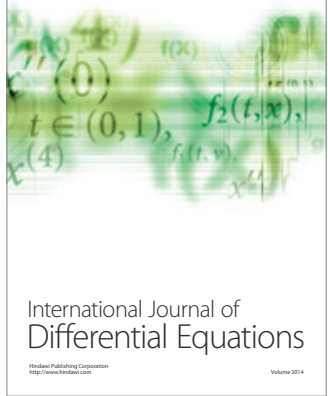
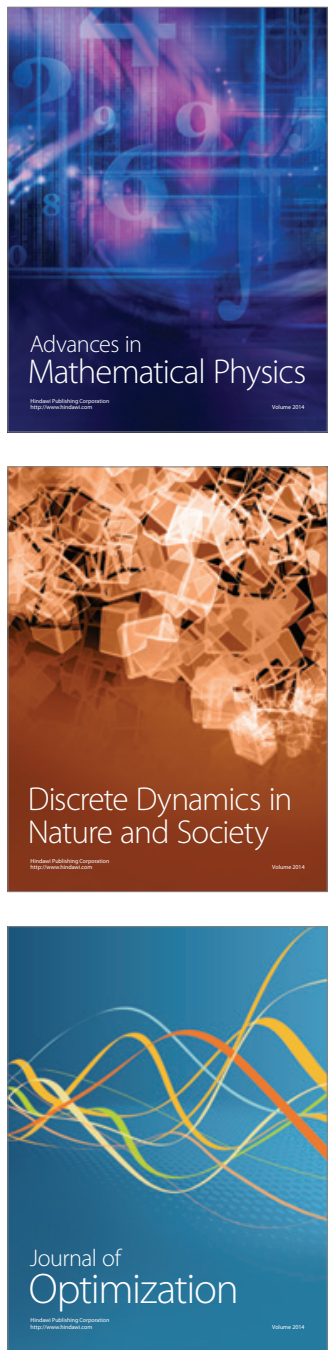